\title{
Effect of Interest Rate on Economic Growth: Swaziland As a Case Study
}

\section{Salami FK ${ }^{\star}$}

Investment Banking, Girne American University, Turkey

\begin{abstract}
This paper analysis the effect of interest rate on the economic growth of Swaziland's economy. The data obtained and analyzed for this study were extracted from world bank data ranging from 1980-2016. The paper aims at determining the effect of inflation rate, deposit interest rate as well as exchange rate on the gross domestic product (GDP) of the country. The ex-post facto research design was selected for this research paper. By ex-post facto research design, it is a quasi-experimental study examining how an independent variable, present prior to the study in the participants affect a dependent variable. A t-test was used for hypothesis testing. For the analysis of data, multiple regression technique was used.
\end{abstract}

Keywords: Interest rate; Exchange rate; Deposit interest rate; Gross domestic product; Ex-post facto design

\section{Introduction}

Swaziland, newly called eSwatini is a landlocked country in Southern Africa and according to its last census count in 2015 the Swazi population is said to be approximately 1.2 million people [1]. There are quite a few countries who still practice absolute Monarchy in present day and Swaziland happen to still be one of them alongside countries like Saudi Arabia, Oman as well as Brunei. Absolute Monarchy as a system of government is well backlashed since the onset for the claim that putting all authority and power in the hand of a single Monarch has been a great source of the economic issues in their various countries. According to The World Economic Forum Report and The Standard Bank Report both dated 2017 stated that for the period of 2010-2014, the Kingdom of Swaziland (presently known as ESwatini) faced its worst economic related crisis with critics claims that the county's executive authority failed to manage its inflation as well as interest rate. Even with this, prior to a paper called "Relationship Between Inflation and Interest Rate in Swaziland" [2], efforts in order to investigate as well as understand the effect of interest rate in present day Swaziland did not well give a full actual understanding in the country's context. Understanding the effect of interest rate on economic growth is a great key to a better economic performance and operation of the country. This study aims at well understanding the effect of interest rate on the country's economic growth if there is really an effect on its economic growth and draw a well understanding conclusion to the research topic.

\section{Aim of study}

The main aim of this research paper is to well define the effect of interest rate on economic growth in Swaziland. The aims of this paper are stated as follow:

- To conclude the effect of inflation rate on economic growth in Swaziland.

- To determine the effect of deposit interest rate on economic growth in Swaziland.

- To decide the effect of exchange rate on economic growth in Swaziland.

\section{Proposed hypothesis}

In this research, the hypotheses are provided in order to examine the relationship between the independent variable and the dependent variable. The below are the proposed hypothesis of this study:
H01: Inflation rate has no significant effect on economic growth in Swaziland.

H11: Inflation rate has significant effect on economic growth in Swaziland.

H02: There is no significant relationship existing between the deposit interest rate and economic growth in Swaziland.

H12: There is significant relationship existing between the deposit interest rate and economic growth in Swaziland.

H03: No significant relationship between exchange rate and economic growth in Swaziland.

H13: There is significant relationship between exchange rate and economic growth in Swaziland.

\section{Literature Review}

This paper as stated earlier aims at examining the impact of interest rate on economic growth in Swaziland. The literature review section of this paper discusses the idea of interest rate and economic growth. In addition to that it also entails theories supporting the topic under consideration but most essentially revises previous related studies to the discussion. It has been taken into note that over the years a country's economic ability to produce well depends on the availability of the economy's resources. For a developing country like Swaziland, the main driver of its economy it's the manufacturing sector and it in return covers for over $45 \%$ of the kingdom's GDP. This sector primarily consists of four major export-oriented industries such as drink processing, fruit canning, sugar processing as well as wood pulp production. According to Adofu [3], a nation's ability to increase its level of production of quality service as well as tangible goods is very well important to the economy's growth. In other words, an increase in a country's Gross Domestic Product is what brings about Economic growth. Inflation and Interest rate are essential macroeconomic

*Corresponding author: Salami FK, Investment Banking, Girne American University, Turkey, Tel: +9039265020 00; E-mail: fskhaleed@gmail.com

Received June 22, 2018; Accepted July 04, 2018; Published July 06, 2018

Citation: Salami FK (2018) Effect of Interest Rate on Economic Growth: Swaziland As a Case Study. J Bus Fin Aff 7: 345. doi: 10.4172/2167-0234.1000345

Copyright: (c) 2018 Salami FK. This is an open-access article distributed under the terms of the Creative Commons Attribution License, which permits unrestricted use, distribution, and reproduction in any medium, provided the original author and source are credited. 
variables capable of changing, transforming and redirecting the growth pattern of a country's economy [4].

In addition to this, the desire of any economy is to have a well maintained economic growth, but the downside is this cannot be achieved where there's a presence of a messed-up interest rate and some scholars claim that inflation and high interest rates happen to be a major setback in economic growth of countries such as Swaziland.

The Neo-classical theory of interest rate which is of present day also known as loanable funds theory, states that the rate of interest like any other form of price is driven by the demand for as well as supply of loanable funds. This theory also indicates that the demand for lendable funds and interest rate move in non-converging directions [5]. From the above, it can be said that any increase in interest rate can negatively affect the cost of raw materials in the country's market thereby leading to an increasing in production cost which brings about threat to the country's economic growth.

Interest rates in simple terms is described as the cost of borrowing money in an economy and it happens to be a major determinant of the cost of credits in an economy. According to Valentino [6], Different types of interest rate are linked and influence each other, so that the functioning of the financial markets and their international relationships explain a good deal of interest rate fluctuations. There are various determinants for the change in interest rate, but this paper is mainly about its effect on economic growth. The implication of this on the economy is that GDP of the economy would be low since equity financing alone cannot adequately sponsor the production activities in an economy [5]. An increase in interest rate can affect the demand for mortgages in the economy thereby negatively affecting the prices of residential real estate in the same economy. The below is a summary of the International Monetary Fund's perspective on interest rate:

- Incentives on the return on financial assets so as to promote deferred consumption which is also perceived as saving for the future activities.

- Interest having been considered as critical aspect of cost of capital that influenced the level of loanable money to the general public [2].

- The domestic interest rates in conjunction with the rate of return on foreign financial assets and goods are hedged against inflation [7].

This paper states the idea of economic growth as the increase in an individual's per-capita income in the economy. An economy is described as grown in a situation where the country's capital dividend by its total population increases sustainability. Economic growth is most of the time described using the value of the economy's GDP. That is, an increase in Swaziland's GDP is considered an increase in economic growth as well. In addition to this, if an increase in the aggregate goods and services per person let's say for a period of 10 years occur, there is chance of economic growth. A nation's economic growth can be measured in terms of its per capital income and the nation's total goods and services within a given period of time [8].
Quite a number of papers have been written and researches conducted on this topic by various nations and a conclusion came about that results might differ depending on the variables taken into consideration or difference in research design and empirical analysis tool.

\section{Research Methodology}

This research paper is driven by the need to test and know the effect of interest rate on the economic growth of Swaziland. This section of the paper shows the data set sample size, variables definition, study population as well as study model specification. This paper assesses annual time series data from the year 1980-2016 with data gotten from World Bank Data Bank as well as the Central Bank of Swaziland [9]. As discussed earlier, the type of research design selected for the paper is the ex-post facto and was selected because there's no incentive to manipulate any of the investigated variable by the researcher and the instinct is mainly to observe economic occurrence of interest rate as well as economic growth over the stated period of time. This paper will extract the given data, interpret as well as test it and derive a conclusion to the topic. The data set will also be examined using the OLS multiple regression technique. Below is a table showing the variables to be observed and their measurements (Tables 1 and 2):

\section{Model specification}

The econometrical Model that will be used for this research paper is stated below:

$\mathrm{GDP}=\beta 0+\beta 1 \mathrm{INF}+\beta 2 \mathrm{DIR}+\beta 3 \mathrm{EXR}+\mathrm{u}$

Where, GDP=Gross Domestic Product

EXR=Exchange Rate

DIR=Deposit Interest Rate

$\mathrm{INF}=$ Inflation rate

$\mathrm{U}=$ Error Terms

$\beta 0=$ constant

$\beta 1=$ is the coefficient of the independent variable (INF)

$\beta 2=$ is the coefficient of the independent variable (DIR)

$\beta 3=$ is the coefficient of the independent variable (EXR)

\section{Data Analysis}

\section{Descriptive statistics}

The elucidating measurements in this piece of the examination portrays and investigations the information utilizing the mean, the standard deviation, the base and the most extreme. The points of interest of the engaging insights are introduced in Table 3 beneath:

The above table shows that a sum of 37 study observations were broke down in this investigation. The table further demonstrates that

\begin{tabular}{|c|c|c|c|c|}
\hline Variable & Name & Measurement & Type \\
\hline GDP & Gross Domestic Product & Measured using the value gotten from CBS & Dependent & GDP (annual \% growth rate) \\
\hline INF & Inflation Rate & Measured using the value gotten from World Bank & Independent & Inflation, GDP deflator (annual \%) \\
\hline DIR & Deposit Interest Rate & Measured using the value gotten from World Bank & Independent & Deposit interest rate $(\%)$ \\
\hline EXR & Exchange Rate & Measured using the value gotten from World Bank & Independent & $\begin{array}{c}\text { Official exchange rate }(\text { LCU per US\$, } \\
\text { period average) }\end{array}$ \\
\hline
\end{tabular}

Table 1: Variables to be observed and their measurements. 
Citation: Salami FK (2018) Effect of Interest Rate on Economic Growth: Swaziland As a Case Study. J Bus Fin Aff 7: 345. doi: 10.4172/21670234.1000345

Page 3 of 5

\begin{tabular}{|c|c|c|c|c|}
\hline Year & GDP & Inflation rate & Exchange rate & $\begin{array}{l}\text { Deposit interest } \\
\text { rate }\end{array}$ \\
\hline 1980 & 12.449052 & 8.2095378 & 0.7788337 & 4.5 \\
\hline 1981 & 14.641441 & 3.5103445 & 0.8775789 & 6.5833333 \\
\hline 1982 & 1.1725679 & 15.179686 & 1.0858158 & 11.666667 \\
\hline 1983 & 1.2023549 & 4.7369214 & 1.1141 & 11.166667 \\
\hline 1984 & 6.1617551 & 11.064967 & 1.4752775 & 15 \\
\hline 1985 & 3.7924157 & 5.9873723 & 2.228675 & 14.381667 \\
\hline 1986 & 12.264478 & 13.916577 & 2.2850317 & 7.59 \\
\hline 1987 & 14.60659 & 1.113117 & 2.0360333 & 4.8883333 \\
\hline 1988 & 6.5698216 & 24.132609 & 2.2734675 & 6.74 \\
\hline 1989 & 12.911104 & 2.8917373 & 2.6226775 & 9.0758333 \\
\hline 1990 & 21.018001 & 30.384907 & 2.5873208 & 8.7408333 \\
\hline 1991 & 1.7603763 & 8.7777505 & 2.761315 & 10.599167 \\
\hline 1992 & 3.2262069 & 11.18825 & 2.8520142 & 10.493333 \\
\hline 1993 & 3.1061142 & 17.389759 & 3.2677416 & 7.89 \\
\hline 1994 & 2.400691 & 10.970427 & 3.5507983 & 7.535 \\
\hline 1995 & 4.8256516 & 16.649381 & 3.627085 & 9.4383333 \\
\hline 1996 & 3.8420536 & 7.6823651 & 4.2993492 & 11.083333 \\
\hline 1997 & 3.1028054 & 11.344841 & 4.6079617 & 12 \\
\hline 1998 & 2.6040394 & 7.405278 & 5.5282842 & 11.916667 \\
\hline 1999 & 2.9508752 & 5.370059 & 6.1094842 & 9.8591667 \\
\hline 2000 & 1.7601738 & 25.342942 & 6.9398283 & 6.53 \\
\hline 2001 & 1.0547649 & 8.9426194 & 8.6091808 & 6.15 \\
\hline 2002 & 4.3800991 & 8.9149283 & 10.540747 & 8.0166667 \\
\hline 2003 & 3.8802136 & 6.0054957 & 7.5647492 & 7.5883333 \\
\hline 2004 & 3.6239142 & 3.8712878 & 6.4596925 & 4.6308333 \\
\hline 2005 & 5.9987766 & 6.5568231 & 6.3593283 & 4.0125 \\
\hline 2006 & 5.9921668 & 4.0411619 & 6.7715492 & 4.93 \\
\hline 2007 & 4.4353756 & 5.0142979 & 7.045365 & 7.0541667 \\
\hline 2008 & 0.8216639 & 10.425576 & 8.2612233 & 8.1666667 \\
\hline 2009 & 1.5650489 & 9.7699243 & 8.4736742 & 5.4033333 \\
\hline 2010 & 3.793755 & 3.1971755 & 7.321222 & 3.8533333 \\
\hline 2011 & 2.2472298 & 5.3409451 & 7.2611321 & 2.85 \\
\hline 2012 & 4.7181557 & 8.0485187 & 8.2099686 & 2.465 \\
\hline 2013 & 6.4208049 & 4.4786825 & 9.6550561 & 2.08 \\
\hline 2014 & 1.93101 & 5.8394666 & 10.852656 & 2.14 \\
\hline 2015 & 0.3911289 & 7.554898 & 12.758931 & 2.27 \\
\hline 2016 & 1.3686941 & 5.2588302 & 14.709611 & 2.94 \\
\hline
\end{tabular}

Table 2: OLS multiple regression technique.

GDP which happens to be the needy variable (i.e. dependent variable) has a mean of 5.107875. This suggests considering the time under scrutiny utilizing the indicator factors in the examination overlooking different variables, the normal GDP can be anticipated to be 5.107875 . The examination additionally demonstrates that the deviation of the GDP from the mean is low (that is, 4.718768), likewise the base and most extreme are 0.3911 and 21.018 individually. Table 3 likewise demonstrates that EXR (exchange rate) has a mean of 5.507102 with a little deviation of 3.531314 and a base and greatest of 0.7788 and 14.7096 respectively. INF has a mean of 9.3651 with a deviation of 6.4808 and at least 1.11312 and greatest of 30.3849. DIR has its mean to be 7.357555 and a standard deviation of 3.484774 . The greatest and least values for DIR remained at 15 and 2.08 separately.

\section{Regression result}

The OLS shapes the significant apparatus for information investigation in this examination. The OLS procedure is chosen in light of the outcome acquired from the Augmented Dickey Fuller test for unit root. The outcomes demonstrated that the rundown insights of the factors under scrutiny took after a pattern and therefore are stationary, consequently a p-VALUE of 0.000 for GDP, 0.0001 for EXR, 0.0047 for DIR and 0.4884 for INF. The OLS was utilized in light of the fact that the information is that of a basic time series and the factors are affirmed to be stationary (i.e. the value were confirmed to be stable and cannot be changed).

Test of significance: To test that the outcomes got from the relapse demonstrate are fit to sum up the discoveries thereto, the model was tried at $5 \%$ level of significance. The outcome from the model show Prob $>F=0.000803$ and a F-value of 7.13. The choice decide is that a likelihood of under 0.05 is noteworthy and fit to sum up the discoveries acquired from the model. In view of the likelihood of 0.000803 acquired from the model which is under 0.05 , it can be inferred that the model is fit for speculation of the outcomes. Additionally, the F-value of 7.13 means that every one of the coefficients are unique in relation to zero. This further affirms the way that the model is fit for utilize.

Table 4 likewise exhibits the rundown of the outcome between economic growth and interest rate as demonstrated by the P-estimations of 0.0047, 0.4884 and 0.0001 for DIR, INF and EXR separately. The outcome additionally unveils that $33.82 \%$ of the variety in GDP is caused by the illustrative factors in this investigation. This infers just $66.18 \%$ of the variation in GDP is accounted for by factors order than the variables investigated within the time covered by the research. The R-square from the table demonstrates an estimation of 39.34\%. The contrast between the R-square and the Adjusted R-square gives an estimation of $5.52 \%$. This implies if the whole populace of the examination were tested, the outcome got from this investigation would have contrasted from that of the whole populace by only $5.52 \%$ inferring that the example stands for $94.48 \%$ of the forecast from the whole populace.

\begin{tabular}{|c|c|c|c|c|c|}
\hline Variable & OBS. & Mean & Std. dev. & Min & Max \\
\hline GDP & 37 & 5.107875 & 4.718768 & 0.39112886 & 21.0180005 \\
\hline INF & 37 & 9.365121 & 6.480803 & 1.11311696 & 30.3849074 \\
\hline DIR & 37 & 7.357555 & 3.484774 & 2.08 & 15 \\
\hline EXR & 37 & 5.507102 & 3.531314 & 0.77883374 & 14.7096109 \\
\hline
\end{tabular}

Table 3: Descriptive statistics.

\begin{tabular}{|c|c|c|c|c|}
\hline Variable & Coefficient & Std. Error & t-Statistic & Prob. \\
\hline INF & 0.071717 & 0.10235 & 0.700696 & 0.4884 \\
\hline EXR & -1.021146 & 0.230696 & -4.426363 & 0.0001 \\
\hline DIR & -0.705135 & 0.232769 & -3.029338 & 0.0047 \\
\hline C & 15.24786 & 2.901125 & 5.255843 & 0 \\
\hline R-squared & 0.393357 & Mean dependent var & 5.107875 \\
\hline Adjusted R-squared & 0.338208 & S.D. dependent var & 4.718768 \\
\hline S.E of regression & 3.838746 & Akaike info criterion & 5.629975 \\
\hline Sum squared resid & 486.2871 & Schwarz criterion & 5.804128 \\
\hline Log likelihood & -100.1545 & Hannah-Quinn Criter. & 5.691372 \\
\hline F-statistic & 7.132584 & Durbin-Watson stat & 1.701313 \\
\hline Prob (F-statistic) & 0.000803 & \multicolumn{4}{|l}{} \\
\hline
\end{tabular}

Dependent variable: GDP

Method: Least Squares

Date: 05/20/2018 Time: 11:02

Sample: 19802016

Included observation: 37

Table 4: Regression result. 
In-depth investigation of the outcomes in table four demonstrates that there is a constant value of 15.25. This means holding the impact of EXR, INF and DIR steady, the GDP of the nation will in any case be at 15.25 . Despite what might be expected, the outcome additionally demonstrates that if every single other factor is held consistent a unit increment in exchange rate would significantly (0.0001) decrease GDP of Swaziland by 1.021146 units. Additionally, if some other factor isn't viewed as separated from that of inflation, a unit increment in inflation rate would insignificantly ( 0.4884$)$ increase GDP by 0.0712 units. Also, a unit increment in deposit interest rate holding every single other factor steady would significantly (0.0047) reduce GDP of Swaziland by 0.705 units.

\section{Policy implication}

The consequences of this examination may have some noteworthy strategy suggestions on local arrangement creators. It is opined that a watchful perception of these approaches may enhance financial development/economic growth in Swaziland.

Exchange rate and economic growth in Swaziland: The outcome from Table 4 is the same as that of prior expression before. It was declared before that increase in exchange rate would negatively affect economic growth in Swaziland. Thusly, the outcome in Table 4 demonstrates that conversion scale has a negative (-1.021146) impact of GDP in Swaziland. Exchange rate can be viewed as the cost of a dollar for the Swazi economy. In this manner as exchange rate expands a greater amount of the naira would be utilized to buy a unit of the dollar; impliedly just a couple of crude materials can be acquired with the currency in the worldwide market. This may result to low profitability and subsequently low GDP in the country. It is essential in this way, to address exchange rate vacillation with the proper strategies in order to stop hindering financial development. The table additionally demonstrates that the impact of EXR is significant (0.0001) to kingdom's economic growth. This means that given the presence of negative effect of EXR on GDP, if not attended to can give a harsh effect of decreasing GDP to a zero level.

Deposit interest rate and economic growth in Swaziland: As predicted that DIR would negatively affect the Nigerian financial development, the outcome from Table 4 demonstrates that DIR have a negative (-0.705135) and significant 0.0047 impact on the GDP of the nation. The suggestion is that as DIR increment the GDP of the nation should likewise increment. This could be connected to the way that DIR are income of the Deposit Money Banks which might be utilized as lendable assets that may support profitability. Likewise, DIR since they are money earned by the holders of the stores, such monies can be transferred once again into the economy by method for reinvestment that may thus enhance monetary development. It is normal that strategy creators on DIR would keep up stable arrangements that would empower stores/deposits so sit out of gear money could be changed over to methods for re-creation or means of production.

Inflation and economic growth in Swaziland: The above test offsets desire in this investigation that inflation rate would negatively affect the financial development of Swaziland [10]. Table 4 additionally demonstrates that INF has a positive (0.071717) impact on the GDP in Swaziland. The ramifications of this outcome is that as long as the inflation rate lessens the GDP of the nation would be on the expanding side. This proposes the control measures for inflation control are very economical. It is imperative in this manner that since inflation can't be completely dispensed with, the nation should attempt however much as could reasonably be expected to control expansion to a solitary digit level. Then on the other side, the outcome likewise demonstrates that the impact of INF on GDP is inconsequential (0.4884). This suggests the lessening in GDP occasioned by the expansion rate factor isn't sufficient to convey the nation's economic growth to an end.

\section{Conclusion}

The principle point of this research paper is to learn the impact of interest rate (loan fee) on the financial development/economic growth in Swaziland. This last segment of the paper talks about the rundown emerging from the discoveries of the investigation. What's more, the conclusion and proposals are examined under this area. The conclusion and the suggestions are additionally in view of the discoveries of the investigation. Moreover, the restriction of the investigation and regions for additionally look into are likewise talked about.

The discoveries of this investigation depend on the information examination. The discoveries in them condense frame is that: interest represent $39.33 \%$ of the variety in GDP. Be that as it may, all the more particularly, it was found that:

INF has a positive $(0.071717)$ and insignificant $(0.4884)$ association with GDP. This infers an expansion in INF will prompt an expansion in GDP anyway the expansion may not be sufficiently critical to absolutely take out development in GDP.

EXR additionally has a negative $(-1.021146)$ yet significant relationship (0.0001) with GDP. This correspondingly suggests an expansion in EXR would prompt a lessening in GDP.

For DIR, it has a negative (-0.705135) and significant (0.0047) association with GDP. This depicts an expansion in DIR would diminish GDP. This might be on the grounds that piece of the loan cost (interest rate) might be reinvested into the economy to increase production which may therefore enhance GDP.

The research paper utilized three intermediaries to describe interest rate; that is, inflation rate, exchange rate and deposit interest rate. On the normal, the outcome exhibit that interest rate have a negative yet huge significance with GDP (economic growth). This is shown by the negative relationship of (DIR and EXR) two out of three logical factors in this investigation to the GDP. Be that as it may, the INF showed a positive relationship with the GDP. In view of the above discoveries, this examination by and large presumes that interest rate has a negative connection with GDP and the cynicism of the relationship is sufficient to absolutely stop financial development in Swaziland if the nation does not roll out improvements.

\section{Recommendation}

After a full conclusion to this study by taken into consideration various necessary variables and regression results gotten and interpreted this paper has a few recommendations. Amongst which includes:

In accordance with the discoveries of this investigation that exchange rate has negative impact on GDP; it is prescribed that strategy creators/government should center around keeping up exchange rate at a low rate and guarantee that the rate is steady. This may moderate the negative impact of exchange rate on GDP as it was discovered to be critical in the nation's monetary development/economic growth.

INF has demonstrated to have positive yet inconsequential relationship with GDP. It is in this way suggests the nation's central bank should expand their observation on the Deposit Money Banks not to build the INF discretionarily as expanding it might not have a decreasing return impact. 
Citation: Salami FK (2018) Effect of Interest Rate on Economic Growth: Swaziland As a Case Study. J Bus Fin Aff 7: 345. doi: 10.4172/21670234.1000345

Page 5 of 5

DIR was likewise found to have a negative relationship with GDP. This negative affiliation might be because of the abnormal state of DIR fluctuating in the Swazi economy. It is suggested that DIR in itself might be the issue as its association with monetary development is well significant. But the high rate of vacillation in the DIR may tote reliable difficulties to GDP and thus economic growth he country's policy makers have to stabilize deposit interest rate in other to increase its economic growth.

\section{References}

1. Mushtaq S, Siddiqui DA (2015) Effect of interest rate on economic performance: Evidences from Islamic and Non-Islamic Economies. MPRA pp: 1-24.

2. Khumalo LC, Mutambara E, Assensoh-Kodua A (2017) Relationship between inflation and interest rates in swaziland revisited. LLC "CPC "Business Perspectives", South-Africa.

3. Adofu I (2010) Accelerating economic growth in Nigeria, the role of foreign direct investment. Current Res J Economic Theory 2: 11-15.

4. Adofu I, Abula M, Audu SI (1988) An Assessment of the Effects of Interest Rates Deregulation in Enhancing Agricultural Productivity in Nigeria. Curr Res J Econ Theory 2: 82-86.

5. Utile BJ, Okwori AO, Ikpambese MD (2018) Effect of interest rate on economic growth in Nigeria. Inter J Advanced Academic Res 4: 66-76.

6. Piana V (2002) Interest Rates.

7. Ojima D, Fabian E (2015) Impact of Interest Rate on Investment in Nigeria Developing Country Studies 5: 103-110.

8. Anyanwu JC (1993) Fundamentals of Economics. Africana First Publishers Limited, Onitcha, Nigeria.

9. Ndzinisa P (2008) The efficacy of monetary policy on economic growth in Swaziland. The Central Bank of Swaziland.

10. Ntshakala PL (2008) Effects of public debt on economic growth in Swaziland. Jomo Kenyatta University of Agriculture and Technology 5: 1-24. 